Relations industrielles

Industrial Relations

\title{
Comment sont organisée les entreprises américaines, Ernest Dale et l'American Management Association, Entreprise Moderne d'Édition, Paris, 1968, 295 pages
}

\section{Pierre Dionne}

Volume 24, numéro 3, 1969

URI : https://id.erudit.org/iderudit/028051ar

DOI : https://doi.org/10.7202/028051ar

Aller au sommaire du numéro

Éditeur(s)

Département des relations industrielles de l'Université Laval

ISSN

0034-379X (imprimé)

1703-8138 (numérique)

Découvrir la revue

Citer ce compte rendu

Dionne, P. (1969). Compte rendu de [Comment sont organisée les entreprises américaines, Ernest Dale et l'American Management Association, Entreprise Moderne d'Édition, Paris, 1968, 295 pages]. Relations industrielles / Industrial Relations, 24(3), 639-639. https://doi.org/10.7202/028051ar

Tous droits réservés (C Département des relations industrielles de l'Université Laval, 1969
Ce document est protégé par la loi sur le droit d'auteur. L’utilisation des services d'Érudit (y compris la reproduction) est assujettie à sa politique d'utilisation que vous pouvez consulter en ligne.

https://apropos.erudit.org/fr/usagers/politique-dutilisation/ 


\section{RECENSIONS}

Comment sont organisée les entreprises américaines, Ernest Dale et l'American Management Association, Entreprise Moderne d'Edition, Paris, 1968, 295 pages.

Ce livre est le fruit d'une vaste enquête menée sous l'égide de l'American Management Association auprès de ses adhérents. Ernest Dale a été chargé de faire le point sur les principes modernes d'organisation, d'analyser les pratiques les plus efficaces, de souligner l'évolution constatée et de mettre en évidence les méthodes d'organisation susceptibles d'accroître les profits.

Une attention particulière est attachée à l'utilisation des objectifs dans l'articulation de l'entreprise, à la direction collégiale et les problèmes croissants de coordination, aux nouveaux modes de structure, au problème de la réduction du nombre des niveaux hiérarchique et à celui posé par la départementalisation en vue d'une meilleure coordination des contrôles, et surtout à la mise en oeuvre de la réorganisation.

L'étude se divise en cinq parties. L'auteur étudie d'abord les fondements de l'organisation; il en explique les principes de base avant de décrire les différentes théories et la détermination des objectifs. L'auteur passe ensuite à la division du travail. Etat-major et hiérarchie, état-major à vocation générale, le chef d'entreprise et ses subordonnés immédiats, organisation fonctionnelle et structure divisionnaire, centralisation ou décentralisation, et les niveaux de direction sont les thèmes tour à tour développés dans cette deuxième partie. Par la suite, l'auteur pose le problème de la coordination et de la réorganisation.

Ce nouvel ouvrage étudie les facteurs récemment apparus dans le domaine de l'organisation, la mesure dans laquelle les entreprises les ressentent et les modifications qu'ils déterminent dans les structures. Ainsi toute personne détenant un pouvoir hiérarchique dans une entreprise aurait avantage à lire cet ouvrage.

Pierre DIONNE.
Retraining the Unemployed, by Gerald G. Somers, editor, the University of Wisconsin Press, Madison, 1968, 351 pages.

Le professeur Somers nous présente huit études de cas de formation de travailleurs en chômage. Par ces études, il veut répondre aux critiques que connaissent actuellement ces programmes de formation. Que valent exactement ces programmes, réduisent-ils le chômage, qu'apportent-ils à la société, à laquelle ils coûtent si cher?

Après, la lecture de l'introduction de G. Somers, après la lecture des huit études, la réponse à ces questions ne fait plus d'équivoque. Les programmes de formation de travailleurs en chômage bénéficient à la collectivité et aux travailleurs eux-mêmes. Les principaux critères pour étudier la profitabilité de ces programmes sont élaborés comme suit: si un fort pourcentage de travailleurs inscrits aux programmes ont pu trouver un emploi, les programmes sont profitables. Les études démontrent en effet que la majorité des travailleurs ont pu réintégrer le marché du travail. Même si les auteurs ne sont pas assurés de la relation directe entre la formation des chômeurs et leur réembauche, ils peuvent à tout le moins affirmer que la relation n'est pas négative. La relation connaît en effet des critères de discrimination (âge, sexe, race, cours suivis) qui ne l'assurent pas à cent pourcent. Contre cette relation positive, les auteurs découvrent d'autres facteurs bénéfiques à la formation des chômeurs, tels l'augmentation proportionnelle de leurs salaires, la diminution donc d'un fardeau pour la société, les gains non-économiques (formation générale, satisfaction, participation), la réduction du chômage.

Après avoir démontré la valeur des programmes de formation des chômeurs, le professeur Somers soulève des questions auxquelles les études de ce volume n'ont pu répondre. Les programmes sontils trop coûteux et comment, si oui, réduire leur coût ? Vaudrait-il mieux d'investir dans des programmes de développement et de sécurité sociale? Faudrait- 